Iberian Journal of the History of Economic Thought

ISSN-e 2386-5768

http://dx.doi.org/10.5209//JHE.58095

\title{
A raíz de Keynesianismos, de Miquel Rubirola
}

Xavier López Andrés y Lluis Barbé ${ }^{1}$

\section{Breviarios sobre keynes, su obra y sus efectos}

Hay mucho que decir en favor de los breviarios. Los productos de erudición los leen los convencidos, y aunque predicar al convencido es una práctica útil, diseminar ideas requiere una agilidad y un estilo determinados. ¿Quizá la agilidad y el estilo en viñetas de Peter Pugh y Chirs Garratt en Keynes para principiantes (2017)? Bueno, es una apuesta arriesgada, el formato puede dar un poco de grima - aunque algunas viñetas recogen aspectos de calado, nada caricaturescos.

De otro lado, cuando un estudiante de economía o un lector interesado cualesquiera desean leer sobre Keynes pueden encallar en la descomunal cantidad de material disponible. Casi le sucedió a Robert Skidelsky. En la introducción de su biografía de Keynes cuenta que "miles de artículos y libros habían aparecido analizando lo que Keynes había dicho, lo que pretendía decir, lo que otros habían dicho, etc. ¿Dónde, en mitad de toda esta exégesis, radicaba mi ventaja comparativa?". El estudiante corriente puede redondear sus apuntes con el capítulo que dedican a Keynes los manuales y los textos de Schumpeter y Heilbroner ${ }^{3}$, pero esta no es una salida natural para el lector ambicioso corriente, sea o no estudiante. Para escoger debe ser resolutivo y proveerse de un resumen como quien se provee de un mapa. Necesita un breviario, un buen texto de hasta (pongamos) unas doscientas páginas.

Con esta restricción, entre los libros breves anteriores a 1970 son muy conocidos Introducción a Keynes, de Raúl Prebisch y Guía de Keynes, de Alvin Hansen, ambos de Fondo de Cultura Económica. En rigor, y pese al título, son unas notas (excelentes) para una lectura de la Teoría General, no unas notas a Keynes ni al keynesianismo. Además, están agotados o descatalogados hace ya muchos años. También se puede echar mano de un Keynesianismo ( $\sin$-s final) de Alessandro Vercelli (1989), de apenas ochenta páginas. Federico Novelo ofreció en 1997 su Invitación a Keynes (FCE), en ciento cincuenta páginas, y se lee muy rápidamente Marc Lavoie (2005) La economía postkeynesiana.

En los últimos diez años - por supuesto, desde 2008-, el interés por Keynes se ha renovado y el número de resúmenes ha crecido muchísimo. Son textos de unas doscientas páginas o menos el epítome de Keynes debido a Skidelsky, y también su Regreso de Keynes (2009). Sin ninguna pretensión de exhaustividad, uno puede adquirir Paul Davidson (2009) John Maynard Keynes; Gilles Dostaler (2012) Keynes y el desempleo; Salvador Moreno (2012) J.M. Keynes: crecimiento económico y distribución de la renta; Miguel-Angel Galindo (2014) Keynes y el nacimiento de la macroeconomía o Juan Hernández (2014) Si Keynes fuera ministro de economía ante la crisis del 2008.

Entre los textos breves más recientes, en fin, están Roger E. Backhouse y Bradley Bateman (2015) John Maynard Keynes. Un capitalista revolucionario; Peter Temin con David Vines (2016) Keynes; el ya citado Peter Pugh y Chirs Garratt (2017) Keynes para principiantes, ilustrado, y Keynesianismos. Una inmersión rápida, de Miquel Rubirola (2017). Hay mucho, muchísimo más material, por supuesto, pero en castellano quizá no mucho más que también sea breve y orientado a una presentación razonable del pensamiento de Keynes y de sus intérpretes posteriores.

\footnotetext{
Xavier López Andrés (profesor UAB)

¿Para cuándo una traducción decente de su título más famoso? Sugiero que Los filósofos mundanos es preferible a Los filósofos terrenales. El antiguo Vida y doctrina fue un puro invento, y no muy bueno.
} 
Si nos centramos en los libros más recientes, el texto de Temin y Vines (diez capítulos, ciento ochenta páginas) lo publicó el MIT en el año 2014. Lleva el subtítulo Useful economics for the World Economy, para destacar que aborda sobre todo el problema de las relaciones entre países, algo de interés evidente en el contexto de la crisis de 2008. La estrategia seguida es poner a Keynes en relación con el pensamiento económico anterior a él, no con el siguiente. No hay referencias a escuelas keynesianas posteriores a Keynes, el keynesianismo aparece como un bloque bastante monolítico hasta hoy, emanado directamente de su fundador. Es un libro estupendo, pero si se trata de conocer a Keynes y de presentar las distintas interpretaciones surgidas, este no es el libro que se debe leer. Los miembros del Circus están listados en las páginas 80 y siguientes Austin y Joan Robinson, Sraffa, Meade, Kahn. Más adelante se recogen algunas aportaciones de Solow y Trevor Swan, Hicks, Harrod... pero nada más, creo. El tono general es muy parecido al de un manual de macroeconomía. Dedica el capítulo 6 al modelo IS-LM, que queda establecido como keynesiano, a excepción hecha del párrafo siguiente (página 106):

[el modelo IS-LM] Fue utilizado ampliamente después de la II Guerra Mundial para explicar el análisis keynesiano, aunque no se puede esperar que un simple gráfico capte las sutilezas del libro de Keynes. Hizo que los argumentos, a menudo tortuosos, del libro de Keynes fueran accesibles para muchos estudiantes, y lo usamos aquí para resumir el pensamiento keynesiano pensado para una sola economía. (Hicks argumentó al final de su vida que el modelo IS-LM era en realidad su propia teoría, no la de Keynes. Pero a pesar de que Hicks articuló con cuidado en qué difería su teoría, el diagrama ISLM sobrevive como representación del pensamiento keynesiano).

Esto es todo. No hay ninguna referencia al hecho que en el modelo IS-LM desaparecieron las interacciones de los individuos dentro del grupo, la naturaleza dinámica de las ideas keynesianas, las expectativas y la incertidumbre, las respuestas del público al cambio, las reservas de Keynes a presentar modelos completa- mente especificados. Algo de todo esto sí aparece en los textos de Backhouse y Bateman, y de Rubirola.

El resumen de Backhouse y Bateman, publicado en inglés en 2011, consta de seis capítulos y ciento noventa páginas - más un apartado final sobre bibliografía keynesiana, ya fuera del texto; en total, casi doscientas veinte páginas. Arranca estableciendo las distintas facetas que hay en Keynes - teórico de la economía, diseñador de políticas económicas, filósofo moral-, partiendo del hecho que:

El Keynes que resucitó recientemente de manera tan repentina no es más que uno de los Keynes que han figurado en el debate público en los últimos cincuenta años. No es el mismo que adquirió fama a mediados del siglo XX [...] tampoco es el Keynes que sufrió el rechazo contundente de economistas y políticos en la década de 1970. [p. 12]

Este es un enfoque idéntico al de Rubirola. De un lado, afirmar que hubo muchos Keynes; del otro, distinguir entre qué dijo Keynes, qué dijeron los que lo interpretaron y qué dijeron los que usaron algunas de sus ideas -o que las descartaron - para desarrollar problemas tratados por él, o problemas poco tratados por él, o no tratados en absoluto por él.

Y, en seguida, otra idea esencial compartida en ambos textos. Backhouse y Bateman afirman que

El bagaje filosófico y moral detrás de su pensamiento [de Keynes] indica una comprensión del mundo que seguramente es única entre los economistas del siglo XX. [p. 24]

En palabras de Rubirola,

[Keynes] aportó ideas y formuló propuestas para encaminar el reto de superar las deficiencias morales y económicas en el capitalismo [p. 18] [...] aspiró a concretar un discurso científico que fuese al mismo tiempo «analítico» y «moral» [que] debía ser de utilidad para orientar la vida económica hacia lo que él consideraba «razonable», «justo»y «bueno». [p. 19] 
Por tanto, los dos textos parten de la misma premisa: existen diversos Keynes, y para entenderlos hay que empezar por el Keynes moral, no por el economista.

Ambos resúmenes desarrollan esta idea en idéntico número de capítulos, seis, pero de forma bastante distinta. Backhouse y Bateman ordenan los cuatro primeros apartados de forma que preparan los dos últimos, dedicados a exponer su interpretación de Keynes: de forma deliberada impulsó una revolución ambigua (capítulo V) porque deseaba que fuese permanente (capítulo VI). A Keynes le importaba alentar la discusión, que se realizaba en todo caso con las nuevas herramientas y con el método que él había preparado.

En lugar de considerar que la ambigüedad y la flexibilidad de la obra de Keynes son un problema, creemos que son la clave para entenderlo mejor. Keynes no estaba interesado en establecer una nueva ortodoxia; por el contrario, cuestionaba cualquier ortodoxia y defendía una revolución permanente. [... Aunque] había algunos puntos con los que estaba comprometido [...] no bastaban para definir una teoría económica única. [p. 193]

Por el contrario, Rubirola sigue un esquema lineal y probablemente más acorde con una exposición general e introductoria. Expone la dimensión política y moral de las ideas de Keynes (capítulo 1), describe la revolución keynesiana (capítulos 2 y 3 ) y después se ajusta a la narración cronológica de los hechos predominio keynesiano (capítulo 4), declive (capítulo 5) y regreso (capítulo 6). Si de lo que se trata es de presentar el personaje y sus epígonos esta estructura tiene mis preferencias. Es sencilla y eficaz. Por supuesto, Backhouse y Bateman también presentan a Keynes de forma breve y ordenada, pero el objetivo es apuntalar su opinión sobre la naturaleza de la revolución keynesiana, no presentar sus efectos. Eso se entiende bien cuando uno termina el libro, pero no antes. En principio, por tanto, el enfoque directo de Rubirola parece mejor que el elíptico de Backhouse y Bateman. Además, el breviario de éstos no reserva mucho espacio a los años posteriores a la muerte de Keynes. Las escuelas keynesianas ulteriores quedan confinadas al capítulo final de bibliografía, magníficamente comentada. Sin embargo, es a través del tamiz de estas escuelas de pensamiento - de modo convencional, síntesis neoclásica, monetaristas y poskeynesianos - que hoy se llega normalmente a Keynes o, peor, se confunden con él.

Como ya se ha dicho, las ciento noventa páginas de Rubirola abordan a Keynes con un lenguaje llano. Esto, sobre todo, no es el resultado de una estrategia de claridad, como en Backhouse y Bateman, sino la consecuencia de su posición de economista no académico, o muy poco académico. Ahora bien, escribir sobre economía como partisano, desde fuera de la academia, es un clásico. Ya les sucedió antes a Ricardo, a Marx y a Veblen por poner sólo tres ejemplos. Lo esencial de Rubirola es que juega desde fuera, y dado que Keynes nunca se encasilló en la academia esto parece muy apropiado. Su trabajo es el de uno de aquellos hombres prácticos que tanto interesaron a Keynes, y eso es una ventaja si se trata de escribir un breviario.

¿Y cómo expone Rubirola las ideas económicas de Keynes? Resume el Breve tratado sobre la reforma monetaria, el Tratado sobre el dinero (capítulo 2) y la Teoría General (capítulo 3). Ahora bien, para ilustrar el núcleo de las ideas keynesianas no las opone a los principios clásicos en general, sino a Hayek y a Churchill en particular. Así obtiene por contraste la posición de Keynes frente a los problemas del desempleo y del mantenimiento del tipo de cambio de la libra - la necesaria reducción de costes, también salariales. Leerlo en las actuales condiciones del mercado de trabajo en la economía española tiene un aliciente nada dudoso, en especial las alusiones a la teoría del monstruo económico.

Rubirola dedica el capítulo cuarto a los keynesianismos de la etapa dorada del capitalismo. Trata de la aparición y difusión de la Síntesis Neoclásica de Samuelson, de la curva de Phillips (que permitía cerrar el sistema) y del paso de la teoría económica a su aplicación en recomendaciones de política económica para la promoción del crecimiento, el pleno empleo y la estabilidad.

La regularidad con la que Samuelson publicó su Curso de Economía Moderna permite ver que la edición de 1955 (en tercera edición de Estados Unidos, edición española de Aguilar de 1960) ya contenía el gráfico ISLM. La curva IS no se llama IS, sino BB, y la curva LM no se llama LM, sino MM, pero 
el gráfico aparece. Está en la página 589, en un lugar muy secundario: dentro de un anexo, metido en una nota extensa a pie de página. En cambio, en la edición anterior (la segunda de Aguilar, correspondiente a la de 1951 en Estados Unidos) no hay ni rastro del gráfico. Sí está el de $45^{\circ}$, pero no Hicks, ni Hansen, ni la expresión síntesis neoclásica, que aparecen a menudo a la edición tercera de Samuelson. Por lo tanto, es plausible fijar la difusión del modelo IS-LM en los manuales docentes hacia (pongamos) 1955, no antes. Hasta donde sé, mientras el gráfico de $45^{\circ}$ siempre aparece en el cuerpo principal de Samuelson, el modelo IS-LM siempre aparece en apéndices, en una posición secundaria. En la edición española de 1991 (que ya es con Nordhaus, la decimotercera americana, creo) sigue ahí aunque Rubirola nos recuerda que el propio Hicks en 1976 ya había abjurado del modelo:

'...pues, de hecho, reducía La Teoría General a unos esquemas de la economía en equilibrio. "El gráfico IS-LM verdaderamente no está al día", afirmó Hicks.'

El capítulo quinto aborda el declive de las corrientes keynesianas, y las controversias con el emergente monetarismo, así como la desregulación y las reformas del Consenso de Washington. El capítulo sexto, último, lo ocupa el regreso de Keynes en el contexto de la crisis de 2008. Rubirola enfatiza aquellos economistas que sí supieron prever la crisis y las limitaciones de los supuestos inmutables asumidos por los modelos matematizados de las expectativas racionales y la Nueva escuela clásica, hegemónicos desde 1980 e incapaces de asumir la existencia de burbujas especulativas.

Keynesianismos, de Miquel Rubirola, es, pues, una ayuda excelente para quienes deseen poner en perspectiva las diversas formas de ser keynesiano. Si el lector se decide por lecturas posteriores tendrá una estructura donde encajar las piezas que encuentre; si se da por satisfecho con este breviario habrá adquirido una geografía muy razonable del pensamiento de Keynes y de las corrientes que derivaron de él.

\section{Expansiones ante un magnífico breviario}

por Lluís Barbé (Profesor emérito UAB)

Keynesianismos es un libro que vale la pena recomendar porque los lectores te agrade- cen después ostensiblemente el consejo. Está muy bien escrito y permite ponerte al día sin esfuerzo. Es el libro ideal para incluir en las bibliografías de cursos a todos los niveles: grados, masters o doctorados, y también para satisfacer a los amigos ansiosos por seguir las corrientes de la Economía.

Lo ha escrito Miquel Rubirola, un economista jubilado con una cierta experiencia política y con menos experiencia en la docencia universitaria. Entonces, cabe preguntarse: ¿por qué no hay muchos más textos llanos y precisos como éste, que faciliten la docencia, producidos por nuestros profesores universitarios?

"La respuesta, amigo mío, nos la sopla el viento", que diría Bob Dylan. Si ponemos atención, el viento del mundo nos dice que si no se soplan estímulos suficientes no habrá repuestas adecuadas. ¿Y qué estímulos hay para que los profesores universitarios escriban textos dedicados a la difusión llana de la historia del Pensamiento Económico? Pues no hay ningún estímulo externo a añadir a la buena fe y la conciencia de cada uno. ¿Y por qué no los hay?

En primer lugar, por el bajo papel académico que se otorga a las diversas historias de la ciencia, cuando son esenciales para compensar la deriva de los especialistas que sólo saben del punto sobre el que destacan. De las cuatro patas de la Retórica que debería utilizar la ciencia para persuadirnos de lo que afirma y que Deirdre McCloskey nos recordó tiempo ha, - datos, lógica, uso de metáforas y narrativa - esta última, que es la madre de la historia, es la más desdeñada por los dogmáticos del neopositivismo lógico. Basta con ver cuán infravaloradas están las revistas de historia del pensamiento económico en los rankings para evaluar la investigación. Por suerte empiezan a haber reacciones - a estas apreciaciones tan miopes - impulsadas desde la base, es decir, por los alumnos que exigen conocer la historia de la ciencia que aprenden, para tener criterio y saber qué, cómo y por qué les están enseñando lo que les están enseñando.

En segundo lugar, por la confusión entre los términos ingleses investigation y research, $-\mathrm{o}$ los franceses investigation \& recherche, $\mathrm{o}$ los catalanes investigació \& recerca, etc.- es decir, entre la indagación de vestigios - el rastro o huella latinos: vestigium - y el intento repetido de dar vueltas - el alrededor latino: circa - a un tema para conocer todos sus in- 
tríngulis y avanzar en su comprensión. Pese a esta diferencia etimológica inicial que ha llevado a usar research o recherche en los nombres de instituciones científicas -National Bureau of Economic Research o Ministère de la Recherche- y a aplicar el término investigation a la tarea de los detectives de todo tipo, los dos términos se han ido utilizando más y más como sinónimos.

En algunas lenguas -el castellano, por ejemplo- el término correspondiente a research, recherche o recerca no existe: todo es investigación. Y cuando se dice aquello de que "no se puede ser un buen profesor si no se es un buen investigador" no se puede rebatir, porque la tarea docente supone saber indagar vestigios de cómo hacer entender todo un programa de clases a los alumnos. Lo que, en cambio, no es necesario ni es razón suficiente para ser un buen docente es ser un as de la recherche o research, es decir, destacar en aquello que en castellano llaman investigación científica.

Todo ello no tendría mayor importancia si no se hubiera condicionado la carrera académica de los profesores universitarios al lema americano del "Publish or perish" —"Publica o perecerás" - exigiendo que el neófito tenga que concentrar la mayor parte de sus esfuerzos, no en perfeccionar su labor docente, mediante la investigación de apoyo a la docencia, sino en dominar el tipo de investigación que las vacas sagradas de la Academia entienden exclusivamente como high research o investigación punta. Y no una investigación punta cualquiera, sino la que lo es desde su punto de vista. En términos de evaluación imponen "a efectos de objetivar niveles" que los libros publicados no cuentan y basta con volver a repasar los rankings de las revistas para saber sobre qué tenemos que publicar para hacer carrera: sobre qué temas, con qué formalizaciones y bajo qué estándares. Nos los marcan las revistas que dirigen las vacas sagradas del mainstream y en Economía domina la matematización, por lo que podríamos describir esta investigación para futuros académicos como investigación top quanta. Todo ello es muy triste porque este montaje heurístico establecido condiciona el futuro de la ciencia, de las universidades y de los universitarios. Europa, impulsada por algunos scholars con Ph.Ds. americanos, se ha adherido al patrón universitario USA y nos hemos quedado sin muchas de las virtudes de la universidad europea clásica, la de antes, la de siempre.

Esto es cuanto me ha venido a la cabeza al reflexionar nostálgicamente sobre este preciso y pedagógico libro. Gracias por haber considerado atentamente estas expansiones mías. 